\title{
Aliando a aprendizagem de conceitos com a construção de modelos didáticos em aulas de Anatomia Vegetal
}

\section{Combining the learning of concepts with the construction of didactic models in Plant Anatomy classes}

\author{
Amanda Knob Back (back.amanda18@gmail.com) \\ Universidade Federal da Fronteira Sul- \\ Bolsista PIBID/CAPES
}

\begin{abstract}
Resumo: Neste trabalho foi confeccionado o modelo didático do corte transversal da folha de Zea mays. O qual possui grande importância na formação, levando em conta que este pode ser utilizado em aulas práticas em sala de aula, uma vez em que no modelo didático os alunos poderão visualizar e manusear o objeto de estudo, facilitando na compreensão de conteúdos de anatomia, inclusive para pessoas com deficiência visual, pois o modelo é tridimensional, contendo assim diferentes texturas. $\mathrm{O}$ uso destas ferramentas de ensino permite que o professor realize suas aulas de forma prática, simples e menos complexa do ponto de vista dos alunos. A visualização de uma estrutura em três dimensões pode facilitar o processo de ensino e aprendizagem nos diferentes níveis de ensino, já que as escolas da rede pública em sua grande maioria não dispõem de microscópio e outros equipamentos que viabilizem a visualização de estruturas microscópicas e facilitem o estudo de ciências. Para a referida construção, tomou- se como base as estruturas visíveis no corte transversal da folha de Zea mays. Buscou-se fidelidade ao que é visto em lâminas das aulas práticas, se teve o cuidado de colocar as estruturas de acordo com suas posições e cores vistas.
\end{abstract}

Palavras-chave: Botânica; Ensino de Ciências; Metodologia de ensino; Zea mays.

Abstract: In this work, the didactic model of the Zea mays leaf cross section was made. Which has great importance in training, considering that it can be used in practical classes in the classroom, since in the didactic model students can view and handle the object of study, facilitating the understanding of anatomy contents, even for visually impaired people, because the model is three-dimensional, thus containing different textures. The use of these teaching tools allows the teacher to perform his classes in a practical, simple and less complex way from the students' point of view. The 


\section{Vol. 2, n. 3 - Edição Especial: Ciclos Formativos em Ensino de Ciências.}

visualization of a structure in three dimensions can facilitate the teaching and learning process in different levels of education, since the majority of public schools do not have a microscope and other equipment that enable the visualization of microscopic structures and facilitate the science study. For this construction, the visible structures in the cross section of the Zea mays leaf were based. Fidelity was sought to what is seen in the slides of practical classes, was careful to place the structures according to their positions and colors seen.

Key words: Botany; Science teaching; Teaching methodology; Zea mays.

\section{INTRODUÇÃO}

Modelos didáticos biológicos como estruturas tridimensionais ou em alto relevo, especialmente quando coloridos são utilizados como facilitadoras do aprendizado, complementando o conteúdo escrito e as figuras planas. Além do aspecto visual, esses modelos permitem a manipulação do material, visualizando-o a partir de vários ângulos, possibilitando uma possível melhora na compreensão sobre o conteúdo abordado (Orlando et al, 2009).

Da mesma forma, conceituando modelo didático, de acordo com o pensamento de Justina et al., 2003 apud Rocha, 2010, p.16:

[...] corresponde a um sistema figurativo que reproduz a realidade de forma esquematizada e concreta, tornando-os mais compreensível ao aluno. Representa uma estrutura que pode ser utilizada como referência, uma imagem que permite materializar a idéia ou o conceito, tornando-os assimiláveis. Os modelos didáticos devem simbolizar um conjunto de fatos, através de uma estrutura explicativa que possa ser confrontada com a realidade.

A construção em si dos modelos acarreta uma preocupação com os detalhes, melhor forma de representá-los, sendo estes fatores necessitados de estudo, agregando assim, no entendimento do conteúdo referido, além de auxiliar a desenvolver habilidades artísticas. Os modelos didáticos podem ser utilizados para enriquecer as aulas de biologia de Ensino Médio, auxiliando na compreensão do conteúdo relacionado. Os modelos despertam um maior interesse nos estudantes, uma vez em que permitem a visualização do processo (ORLANDO et al, 2009). 


\section{Vol. 2, n. 3 - Edição Especial: Ciclos Formativos em Ensino de Ciências.}

Conforme anteriormente citado, comumente nas escolas espaços laboratoriais não se fazem presentes, ou sua estrutura não é adequada, ou ainda há a sua subutilização. Desta forma, há a dificuldade de visualização de estruturas microscópicas nas aulas de ciências e biologia, estando elas então restritas a esquemas e imagens que na maioria das vezes se detém aos presentes nos livros didáticos. Sendo assim, a utilização de um modelo didático tridimensional rompe com estas barreiras, viabilizando uma visualização que tem alto potencial de se demonstrar altamente proveitosa não apenas quando não há recursos para visualização laminar como também em sua presença.

Reitera-se que o modelo didático é uma ferramenta passível de auxiliar no processo ensino-aprendizagem, demonstrando assim sua importância. Logo, a finalidade deste trabalho é construir um modelo didático referente ao corte transversal do Zea mays, ou seja, milho. Com intuito de despertar o interesse dos alunos pelo estudo de plantas, mostrando que uma simples folha pode ter um amplo sistema de células, podendo ver detalhes que somente a microscopia facilita, enfocando na anatomia de uma folha internamente e como são os processos dentro de uma planta.

Assim sendo, os modelos didáticos contribuem para uma visualização estrutural que não se limita ao recurso de microscopia ou de imagens/ esquemas, uma vez em que a observação em laboratório requer toda uma estrutura, que muitas das vezes não se encontra presente nos espaços escolares. Correlacionado a este fator, comumente na anatomia vegetal há uma dificuldade de compreensão por parte dos alunos das inúmeras estruturas de plantas, ou esta se dá de maneira distorcida. Logo o modelo didático pode se mostrar como um grande auxílio para o melhor aprendizado e entendimentos de conteúdos e estruturas da anatomia.

Assim com cita Beserra e Brito (p.70):

É cada vez mais necessário o uso de inovações didáticas no ensino de Ciências e Biologia, tanto para alunos de Ensino Fundamental quanto do Ensino Médio. Essas inovações são consideradas um meio de buscar novas soluções para velhos problemas de ensino e aprendizagem. Tais soluções se concretizam como estratégias que buscam a interação dos alunos com a Ciência e com o tema tratado.

Deste modo, a construção de modelos didáticos propicia a aproximação do aluno com aquilo que está sendo ensinado o que torna o conhecimento sistematizado e 


\section{Vol. 2, n. 3 - Edição Especial: Ciclos Formativos em Ensino de Ciências.}

coerente. Vale ressaltar também que estas modelagens podem, também, serem introduzidas em outros componentes curriculares, como por exemplo: aulas de zoologia, na construção de células, órgãos, ou seja, tudo que possui alguma análise morfológica.

\section{DESCRIÇÃO DAS ATIVIDADES}

Este projeto consistiu em uma pesquisa exploratória, ou seja, buscaram-se mais informações sobre a folha do Zea mays, mais precisamente sobre a anatomia vegetal da mesma. Posteriormente foi construído um modelo didático, representando o corte transversal da folha do milho (Zea mays), o qual foi o foco do modelo, também foi demonstrado a parte superior da folha. Este foi elaborado com aproximadamente dois quilogramas de massa de biscuit e tintas guache vermelha e verde, sob uma base composta por duas capas de caderno (grandes) revestidas com folha de ofício e uma base menor de massa de biscuit. Para a referida construção, nos embasamos nas estruturas visíveis na lâmina do corte transversal de Zea mays, conforme a imagem abaixo.

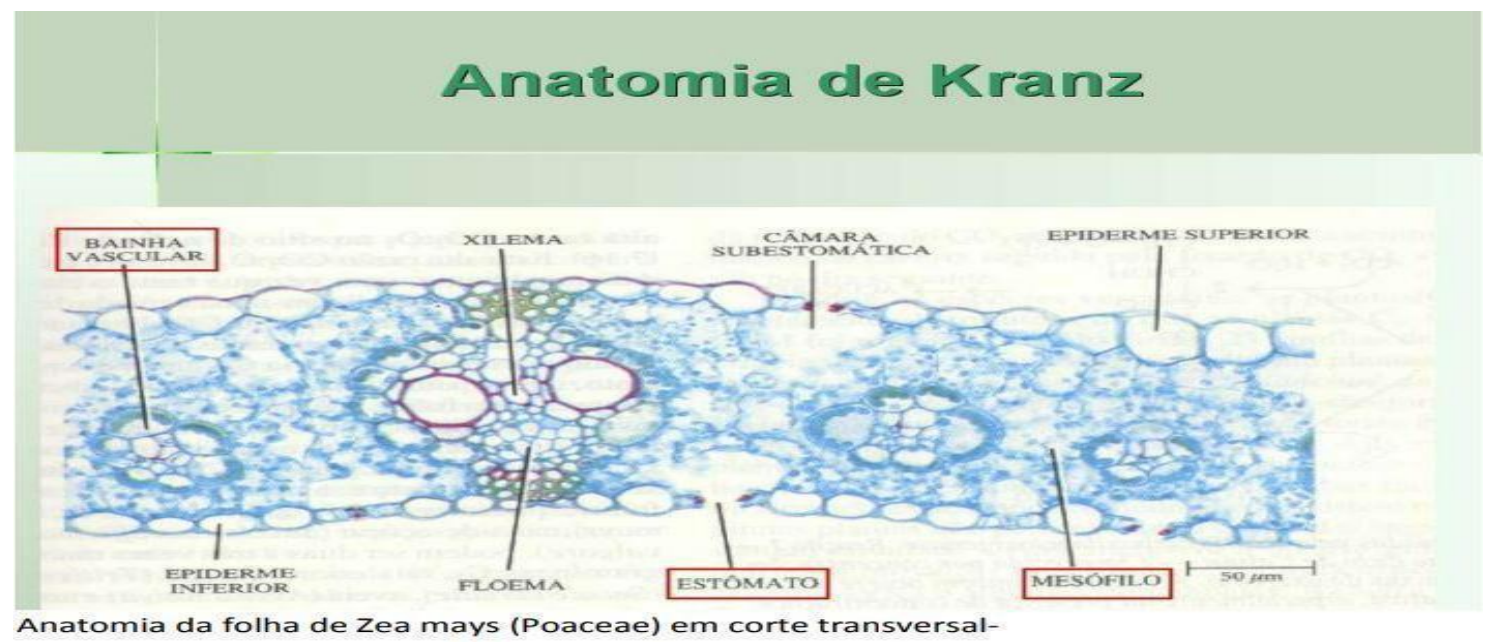

Fonte: Raven 2001; Representação da Anatomia da folha de Zea Mays;

Primeiramente com a base já confeccionada, a massa de biscuit foi dividida em diversos fragmentos, sendo que uma pequena parte desta foi colorida de verde para 


\section{Vol. 2, n. 3 - Edição Especial: Ciclos Formativos em Ensino de Ciências.}

fazer as células guarda dos estômatos, logo utilizando outra porção ainda não colorida para fazer todas as células internas e externas da estrutura separadamente para posteriormente juntá-las. Após foram feitos cilindros de cor vermelha para representar o metaxilema utilizando dois materiais, o biscuit e o papel do tipo cartolina. Já para representar o protoxilema também de cor vermelha, com cilindros menores, foram utilizados biscuit e canudos de plástico, juntado posteriormente com estruturas feitas para representar a bainha do feixe com cloroplastos, maiores e mais desenvolvidos, os quais foram marcados na massa de biscuit com caneta verde, característica de plantas com anatomia C4 e o mesofilo homogêneo.

Também para representar o floema, tecido condutor constituinte do feixe vascular, foram feitas bolinhas de massa de biscuit e que depois foram fixadas com cola de artesanato, estas sendo pintadas com caneta azul. Para preencher o interior da estrutura foi utilizado papel toalha, pois assim foi possível deixar o modelo mais leve para um melhor manuseio, além da economia na quantia da massa de biscuit. Em seguida utilizou-se EVA para fazer a epiderme do formato do milho (mais retas e sem espaços intercelulares), logo foram inseridos os estômatos com o formato de halteres (do tipo do milho), estabelecendo então uma estrutura de formato quadrangular em 3D. Para sinalizar a localização de cada estrutura foram utilizados palitos de dente com papéis colocados de forma semelhante a bandeiras, cada qual com seus determinados nomes facilitando assim o entendimento do modelo.

\section{DISCUSSÃO DO RELATO}

Em relação à aplicabilidade do modelo didático como facilitador de ensino/aprendizagem, fica evidente a busca por estas e outras metodologias capazes de ensinar além daquilo que é proposto em sala de aula, ou além do que está ao alcance do aluno e professor. Assim, destacado por Cardoso, Castro e Silva (2003, p. 152):

Faz parte da formação do profissional docente a busca de novos recursos que complementem e enriqueçam sua atividade de ensino. Um dos grandes problemas do ensino de ciências e de biologia é a pouca compreensão dos alunos na tridimensionalidade inerente aos organismos e às estruturas biológicas observadas somente em lâminas ao microscópio ou na bibliografia especializada. 


\section{Vol. 2, n. 3 - Edição Especial: Ciclos Formativos em Ensino de Ciências.}

Assim como cita Ceccantini (2006), que o aluno a reflete sobre as estruturas de maneira a se aprofundar na sua compreensão tridimensional. E, a construção dos modelos realizados pelos alunos utilizando materiais simples (cartolina, acetato, isopor) como massas plásticas (massa de modelar, biscuit, porcelana fria), gesso ou materiais reciclados (PET, plástico bolha) é muito empregada no ensino fundamental e médio, no entanto, não muito utilizada no ensino superior.

A elaboração do modelo didático tridimensional da folha do Zea mays exigiu tempo, muita dedicação e fidelidade em relação à lâmina e suas respectivas partes para que todas fossem possíveis de visualizar e compreender.

Foi realizada a apresentação em sala de aula, no componente curricular Prática de ensino em ciências/biologia IV: laboratório de ensino de ciências. Esta constava com alunos da disciplina e professores do $4^{\circ}$ semestre de Ciências Biológicas Licenciatura do campus Cerro Largo.

Desde o início da construção até a sua finalização não foram medidos esforços. Foi realizado a confecção do modelo com base na imagem destacada acima, uma microscopia, e a imagem a seguir representa o modelo já confeccionado e finalizado.

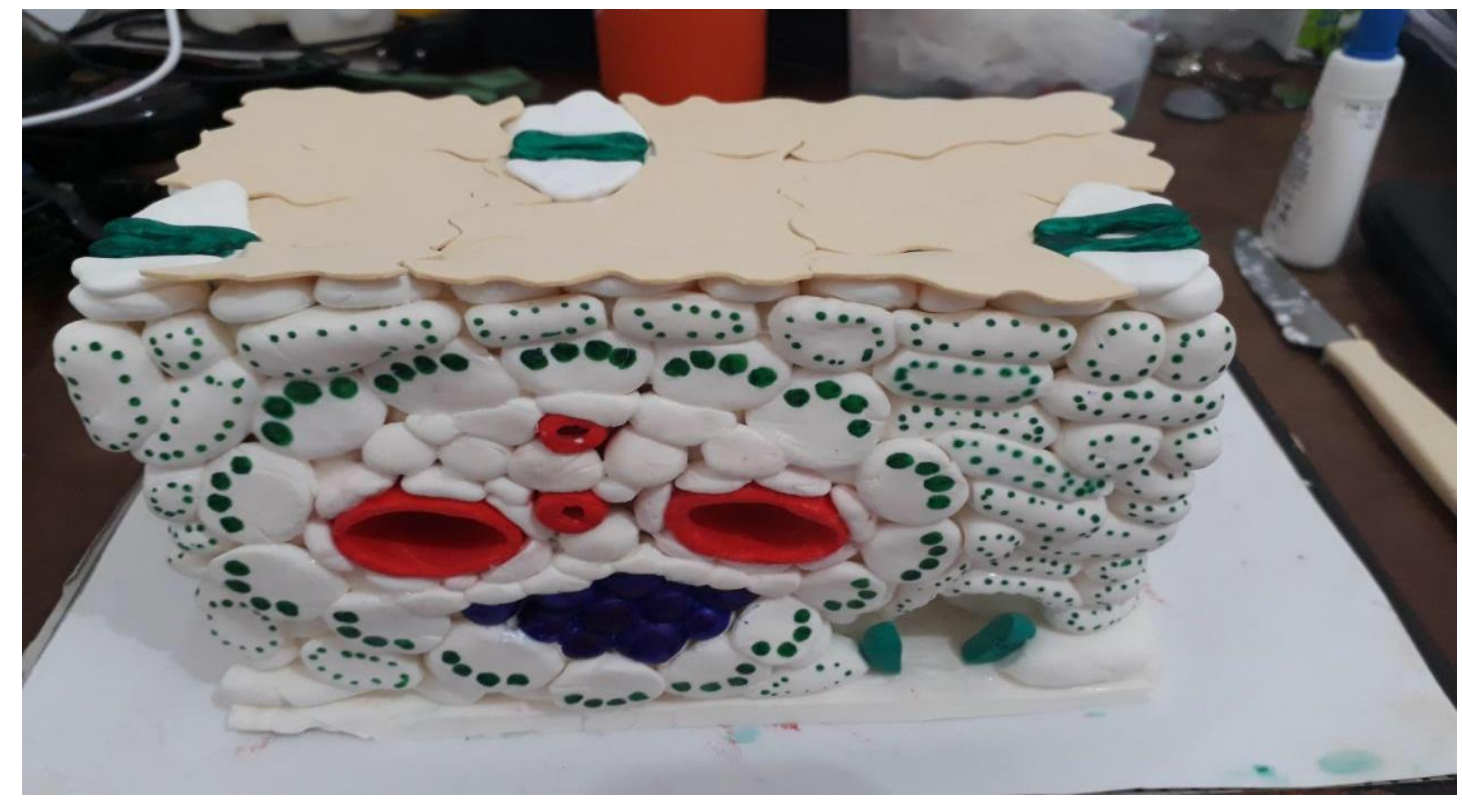

Fonte: autor Modelo didático da Anatomia da folha de Zea mays finalizado. 


\section{Vol. 2, n. 3 - Edição Especial: Ciclos Formativos em Ensino de Ciências.}

\section{CONCLUSÃO}

As metodologias constituem um aspecto fundamental da prática docente, assim sendo, o professor fica como responsável por selecionar as estratégias e recursos que melhor mobilizem a aprendizagem de seus alunos, a fim de aproximá-los dos conhecimentos científicos.

A realização de atividades práticas de sala de aula faz-se necessária para que assim cheguem à tona sentidos e percepções antes nunca vislumbradas e que estas aflorem e que desta maneira ocorra a apropriação dos conteúdos.

A elaboração do modelo acabou por desenvolver a percepção da relevância da representação estrutural de estruturas microscópicas, pois esta tem potencial de auxiliar na demonstração de tais estruturas. Contribuiu assim, para a ampliação do conhecimento, viabilizando maior compreensão e clareza da anatomia da folha e suas estruturas. Através da elaboração do modelo, fez se notório o fato de que a representação de estruturas microscópicas não precisa se restringir ao espaço laboratorial e microscópio, podendo facilmente ser representada de maneira relativamente simples e ainda assim satisfatória no que se refere a presença e disposição das estruturas.

Assim, como aborda Ceccantini o aspecto lúdico e criativo pode transformar uma aula de anatomia vegetal em uma metodologia divertida e agradável. Por vez, há rejeito na criação e diversão no ensino. E estas metodologias estão sendo inseridas para quebrar estes paradigmas, e trabalhar com conceitos considerados complexos. E, estes modelos podem sanar as deficiências nos recursos didáticos, cada vez mais frequentes na Universidade Brasileira.

A construção de modelos didáticos pode e deve ser aplicada e pode ser utilizada em aulas de zoologia, na construção de células, tecidos... enfim, pode ser oportunizado diversas matérias curriculares, pois a modelagem didática pode ser realizada de modo aceitável em qualquer análise morfológica com o intuito de facilitar o ensino de Ciências e Biologia.

\section{REFERÊNCIAS}


Vol. 2, n. 3 - Edição Especial: Ciclos Formativos em Ensino de Ciências.

BESERRA, J. G.; BRITO, C. H. Modelagem didática tridimensional de artrópodes, como método para ensino de ciências e biologia; R. Bras. de Ensino de C\&T, 2011.

CARDOSO, N. S.; CASTRO, M. M. M.; SILVA, J. R. F. A busca de novas ferramentas para a atividade docente no ensino de embriologia e histologia: modelos tridimensionais. In: Encontro Nacional de Biólogos. Natal, 2003, p. 151-152.

CECCANTINI, G. Os tecidos vegetais têm três dimensões. Disponível em: <http://www.scielo.br/scielo.php?pid=S0100-84042006000200015\&script=sci_arttext >. Acesso em: 21 out. 2018.

JUSTINA L. A. D.; RIPPEL J. L.; BARRADAS C. M.; FERLA M. R. Modelos didáticos no ensino de Genética. In: Seminário de extensão da Unioeste, 3., 2003, Cascavel. Anais do Seminário de extensão da Unioeste. Cascavél; 2003. p.135 - 40.

PORTO, A. C. Zea mays. Disponível em: <https://www.tudosobreplantas.com.br/asp/plantas/ficha.asp?id_planta=372068>. Acesso em: 21.out.2018. 